\title{
Thermal fatigue evaluation of AISI H13 steels surface modified by gas nitriding with
} pre- and post-shot peening

Liu, Bin; Wang, Bo; Yang, Xudong; Zhao, Xingfeng; Qin, Ming; Gu, Jianfeng

\section{Published in:}

Applied Surface Science

Link to article, DOI:

10.1016/j.apsusc.2019.03.291

Publication date:

2019

Document Version

Peer reviewed version

Link back to DTU Orbit

Citation (APA):

Liu, B., Wang, B., Yang, X., Zhao, X., Qin, M., \& Gu, J. (2019). Thermal fatigue evaluation of AISI H13 steels surface modified by gas nitriding with pre- and post-shot peening. Applied Surface Science, 483, 45-51. https://doi.org/10.1016/j.apsusc.2019.03.291

\section{General rights}

Copyright and moral rights for the publications made accessible in the public portal are retained by the authors and/or other copyright owners and it is a condition of accessing publications that users recognise and abide by the legal requirements associated with these rights.

- Users may download and print one copy of any publication from the public portal for the purpose of private study or research.

- You may not further distribute the material or use it for any profit-making activity or commercial gain

- You may freely distribute the URL identifying the publication in the public portal 


\section{Thermal fatigue evaluation of AISI H13 steels surface modified by gas nitriding with pre- and post-shot peening}

Bin Liu ${ }^{\mathrm{a}}$, Bo Wang, ${ }^{\mathrm{b},}$ Xudong Yang, Xingfeng Zhaoc, Ming Qinc, Jianfeng Gu ${ }^{\mathrm{a},{ }^{*}}$

a School of Materials Science and Engineering, Shanghai Jiao Tong University, Shanghai 200240, China

${ }^{b}$ Department of Mechanical Engineering, Technical University of Denmark, Kongens Lyngby 2800, Denmark

${ }^{c}$ Hitachi (China) Research Development Corporation, Shanghai 200020, China

In this work, the $\mathrm{H} 13$ hot work die steels were surface modified and experimentally evaluated in a homemade thermal fatigue simulation tester. Two types of nitrided compound layers, and compound-free layers with and without surface deformation were prepared by a selection of surface modifications including traditional gas nitriding, controlled gas nitriding, gas nitriding with pre-shot peening, and controlled gas nitriding with post-shot peening. Thermal cracks formed in the nitrided compound layer propagated faster on surface but slower along the depth direction as compared to those in the compound-free layer. Thermal crack advancing along the depth direction in the sample nitrided with pre-shot peening had a tendency to be suppressed by the higher cross-sectional hardness distribution. The deformed compound-free nitrided layer showed the excellent thermal fatigue cracking resistance in both surface and cross-section, which was attributed to the good combination of hardness and toughness, as well as the underlying enhanced compressive residual stress. Keywords: Hot work die steel; Gas nitriding; Shot peening; Thermal fatigue; Thermal cracking

\section{Introduction}

Pressure die casting is an excellent rapid bulking forming process for high-

\footnotetext{
* Corresponding authors.

E-mail address: bwang@mek.dtu.dk(B. Wang), gujf@sjtu.edu.cn (J. Gu).
} 
precision aluminum castings with complex shapes [1]. During each casting cycle, the molten aluminum $\left(670-710^{\circ} \mathrm{C}\right)$ is injected into the internally cooled mould at high velocity, typically within the order of milliseconds. The dies are continuously subjected to repeated surface thermal-mechanical loadings and overall externally cooling, causing dimensional variation and thermal stress and, consequently, the thermal fatigue failure [1-3]. Thermal fatigue is one of the life-limiting factors of the hot work dies. The typical symbol of thermal fatigue failure in hot work dies is heat checking, which is characterized by the network of small cracks in the die surface after a sufficient number of cyclic thermal and mechanical loading. With the progress of casting, the thermal cracks will propagate rapidly in die surface and penetrate a limited surface layer along the vertical direction [3]. Delay of the crack initiation and suppression of crack propagating, therefore, can both provide positive effect in prolonging the die lifespan and decreasing the production cost [4-6].

Surface engineering of physical vapor deposition (PVD), nitriding, boronizing, etc. can decrease the damage of corrosion and wear on dies through the formation of the continuous compound layer, serving as effective isolating between the molten metal and dies surface [6-11]. Especially a few surface modification technologies are beneficial to improving the thermal fatigue resistance due to the enhanced surface hardness and induced residual compressive stress [9-11]. Gas nitriding as a typical surface thermal-chemical technology can provide excellent process controllability, adaptability and low processing cost $[11,12]$ and has been extensively adopted in the industrial community to resist thermal failure of die casting mould [13-15]. Practical application of gas nitriding on hot work die steel is based on the supersaturation of nitrogen of the ferrite matrix, the precipitation of nitrides and the generation of the compressive residual stress [14]. According to the research from Persson [3], gas nitriding increased both the maximum crack length and the crack density, while the majority of crack arresting effect was reflected in the tough nitrided diffusion layer. Min [7] and Pellizzari [14] demonstrated that a thinner and compact nitrided compound layer is expected to show the better thermal fatigue resistance behavior. Kundalkar [13] indicated that the thermal fatigue resistance decreased with the increase of phase ratio 
of $\varepsilon-\mathrm{Fe}_{2-3} \mathrm{~N}$ and $\gamma^{\prime}-\mathrm{Fe}_{4} \mathrm{~N}$ in the nitrided layers. Apparently, gas nitriding has to be appropriately controlled and performed to provide sufficient resistance against thermalmechanical loading. The scientific challenge is not only to clarify the responses of the single formed nitrided compound layer/diffusion layer to thermal fatigue, but also to combine the specific advantages of each nitrided layer to maximize the thermal fatigue resistance.

In our previous research, a combined treatment of controlled gas nitriding and surface severe deformation was developed to form a severely deformed compound-free nitrided layer in surface of the AISI 4140 steel. The combined treated layer presented a good combination of hardness and toughness. Additionally, the significantly enhanced compressive residual stress was expected beneficial to resist thermal/mechanical loadings [16]. In the present work, the effect of gas nitriding with pre- and post-shot peening on thermal fatigue property was preliminarily evaluated based on the comparably investigation of heat checking behavior in the single nitrided compound layer and compound-free layer. The internal relation between thermal cracks initiation and propagation behavior with the evolution of surface microstructure, toughness, and distribution of hardness was analyzed. Prospects of developing the tailored nitriding process to resist thermal fatigue were discussed.

\section{Experimental procedure}

\subsection{Samples preparation}

A typical hot work die steel H13 with the chemical composition (mass\%) of 0.37 C, $5.13 \mathrm{Cr}, 1.23 \mathrm{Mo}, 0.95 \mathrm{Si}, 0.83 \mathrm{~V}, 0.36 \mathrm{Mn}, 0.009 \mathrm{P}, 0.001 \mathrm{~S}$ and bal. Fe was employed in this study. The steel plates with size of $70 \mathrm{~mm} \times 30 \mathrm{~mm} \times 10 \mathrm{~mm}$ were oil quenched from $1030{ }^{\circ} \mathrm{C}$, and twice tempered at $610{ }^{\circ} \mathrm{C}$ for $2 \mathrm{~h}$ to develop a uniform tempered martensitic structure with a hardness of 480 500 HV. Prior to nitriding/shot peening treatments, the samples were surface grinded, followed with being washed with acetone and absolute alcohol. Gas nitriding was carried out in flowing pure ammonia gas at $550{ }^{\circ} \mathrm{C}$ for $10 \mathrm{~h}$ and $15 \mathrm{~h}$ under corresponding nitrogen potential of 2.80 and 0.18 
respectively, with the aim of forming the nitrided compound layer and compound-free layer. The nitriding potential of 2.80 corresponds to a commonly used ammonia dissociation degree, while the potential of 0.18 should be realized by controlling the ammonia dissociation degree and the flowing rates. Thus, these two processes are dubbed here as traditional gas nitriding (TGN) and controlled gas nitriding (CGN), respectively. The microstructure characteristics of the nitrided layers have been observed in the previous work [10]. Standard steel shots S230 with diameter of $0.6 \mathrm{~mm}$, using an air blast machine were employed to conduct shot peening with peening intensity of $0.30 \mathrm{~mm} \mathrm{~A}$ and coverage of $200 \%$. Shot peening as a pretreatment was introduced on the sample nitrided at $550{ }^{\circ} \mathrm{C}$ for $10 \mathrm{~h}$ under nitrogen potential of 2.80 (SPGN), whereas the post-shot peening was conducted in the compound-free nitrided layer to ensure that no brittle cracks would be generated (CGNSP). Surface phase structures of the surface-modified samples were identified with a D/MAX-PC 2500 Xray diffraction $(\mathrm{XRD})$ by using $\mathrm{Cu} \mathrm{K} \alpha(40 \mathrm{~mA}$ and $40 \mathrm{kV})$ radiation. The depthdependent hardness of the nitrided and combined nitrided samples was measured using a FM-ARS 9000 micro-Vickers hardness tester with a load of $200 \mathrm{~g}$ and dwelling time of $10 \mathrm{~s}$.

\subsection{Thermal fatigue test}

Thermal fatigue tests comprising the cyclical induction heating and high-pressure water cooling were carried out on a home-made thermal fatigue device which mainly consists of the induction heating coil, cooling system, and the movable mechanical thimbles (Fig. 1). Fig. 2 illustrates the evolution of temperature in the surface of the fatigue sample in function of induction heating time as determined using temperature monitoring system equipped with a K-type thermocouple. It takes $5.50 \mathrm{~s}$ to heat the sample surface from room temperature to $670^{\circ} \mathrm{C}$ which is almost equal to the actual temperature of the hot work die during aluminum die casting. Ten seconds of water treatment was adopted as the subsequent cooling process, after which the surface temperature of the sample could be decreased to room temperature. Inset in Fig. 2 shows the geometry of the cylindrical sample, which was cut from each treated steel 
plate. After thermal cycling treatment for 20 to 500 times at atmospheric environment, the samples were socked in a dilute hydrochloric acid solution for 1 3 minutes, depending on the surface condition, to remove the oxide layer and surface contamination. Evaluation of thermal fatigue properties was achieved by measuring the density and length of the thermal cracks on a ZEISS HAL 100 optical microscope (OM) and a laser confocal microscope (OLYMPUS LEXT).

\section{Results}

\subsection{Surface modified layers}

Fig. 3 shows the X-ray diffractograms of the nitrided samples and the combined treated samples. After TGN and SPGN treatments, the surface layer contained strong diffraction peaks of $\varepsilon-\mathrm{Fe}_{2-3} \mathrm{~N}$ and $\gamma^{\prime}-\mathrm{Fe}_{4} \mathrm{~N}$ phases, indicating the continuously formation of the compound layer. Additionally, the surface of the SPGN sample presented the higher phase ratio of $\varepsilon-\mathrm{Fe}_{2-3} \mathrm{~N}$ and $\gamma^{\prime}-\mathrm{Fe}_{4} \mathrm{~N}$, which could be estimated from the XRD results. This could be attributed to the large excess energy generated by the surface severely deformation, which constitutes an extra driving force for the nitride formation process [17]. It is proved that the grain size of the nitrides in the gas nitrided compound layer was in the scale of sub-micrometer, whereas those in the compound layer synthesized with pretreatment of surface deformation is finer, commonly in the order of nanocrystallization $[18,19]$. Coupled with the increase of the lattice strain, the diffraction peak broadening could be noticed relative to those of the single nitrided compound layer. Only $\alpha$-(Fe, $N)$ phases was detected in the diffractograms of the CGN samples before and after shot peening treatment, verifying that no new phase was introduced by shot peening with the exception of a slight diffraction peak broadening.

Hardness-depth profiles of the surface modified samples treated under different conditions are shown in Fig. 4. The maximum value of the micro-hardness appeared at the surface of all treated samples and then it gradually decreased to the core value. The sample nitrided with pretreatment of shot peening showed the highest hardness distribution, which could be attributed to the formation of the compound layer and the 
higher nitrogen diffusion rate caused by the induced micro defects [20,21]. It is worth noting that the hardness in the region extremely close to the surface of the CGN sample ( $\sim 50 \mu \mathrm{m}$ ) was increased after subsequent shot peening treatment. Based on the criterion that the effective case thickness was calculated from the micro hardness profiles as a depth where the hardness is equal to the core hardness plus $50 \mathrm{HV}$ [22], the effective case thicknesses of the modified layers are measured to be in the range from 160 to 187 $\mu \mathrm{m}$.

\subsection{Thermal fatigue behavior}

\subsubsection{Thermal crack initiation growth}

Fig. 5 illustrated the initial growth characteristics of the surface thermal cracks in each surface-modified sample after 50 cycles of thermal fatigue testing. It is seen that the surface grinding marks were more evident than before, and a small amount of new thin thermal cracks perpendicular to the grinding marks formed on the surface of all samples. This indicated that the grinding marks would be one type of the prefabricated crack, and the newly surface thermal cracks already nucleated and developed to the initial growth stage. Formation of the cracks covering the local surface layer demonstrated that the thermal cracks were selectively initiated, proving the theory that the location of the fatigue cracks is correlated with regions existing the largest stress concentration $[3,4]$. Both the grinding marks and the thermal cracks in the compound layer (Fig. 5a and 5c) were thicker than those in CGN samples before and after shot peening (Figs. 5b and 5d), which may be closely related to the brittleness of the compound layer. Apart from the thermal cracks, the oxidation corrosion pits with random distribution could be detected in surface of the shot peened samples (Fig. 5c and 5d). It can be concluded that the surface deformed microstructure promoted the formation of the oxidation corrosion pits, which might provide the formation conditions for the thicker cracks. Thermal fatigue process exposing to air is closer to the thermal condition in the practical production site, but the surface oxidation made it difficult to clearly observe the crack nucleation behavior. 


\subsubsection{Thermal crack propagation}

Thermal crack propagation behavior in the surface of the nitrided samples after thermal cycles from 100 to 500 are illustrated in Fig. 6. Clearly, with increasing the thermal cycles, both width and length of the surface thermal cracks in all the nitrided samples were increased. The TGN samples treated with thermal cycles less than 300 times showed a propagation behavior analogous to formation of intergranular cracks (Fig. 6a and 6b), whereas a severe fatigue surface with no regular pathway appeared in the sample under serious thermal cycling conditions (Fig. 6c). The surface morphology of the thermal treated TGN samples was changed from a rock candy-like structure to a palisade shape with the aggravation of thermal fatigue. Fig. 6d-e show the surface cracks in CGN sample resulting from the thermal fatigue under the same conditions of temperature. Under the same conditions of thermal cycling, a small number of thermal cracks with shorter length appeared in the surface of the CGN sample when compared with those in the TGN samples. Moreover, the thermal cracks grew slowly in compound-free surface layer than those in the compound layer. No traces of crack intertwining were observed in the thermal fatigue surface of the CGN sample even after 500 thermal cycles treatment (Fig. 6d), indicating a lower crack propagation rates. Apparently, the nitrided compound-free layer shows more excellent thermal fatigue property than compound layer in resistance to surface heat checking.

Distinct difference in surface thermal crack propagation characteristics in samples combined treated by gas nitriding and shot peening was observed, as shown in Fig. 7. For the SPGN samples, the thermal cracks in the compound layer propagated particularly fast during the thermal test from 300 to 500 cycles (Fig. 7a-7c). This might be attributed to the formation of thicker compound layer which contains more pores and defects, acting as stress intensifiers and causing stress concentration during thermal cycling [14]. The widest cracks characterized by mesh distribution appeared in surface of the SPGN sample tested after 500 thermal cycles (Fig. 7c). The evolution process of the cracks in the CGNSP samples (Fig. 7d-7e) clearly showed that the cracks extended primarily along the grain boundaries, accompanied by the grain coarsening. Among all 
the surface-modified layers treated by 500 thermal cycles, the deformed compound-free layer contains the narrow thermal cracks with high-density.

Fig. 8 shows the typical microstructure of longitudinal cracks in the cross-section of the surface modified samples tested after 500 thermal cycles. Under the given thermal fatigue conditions, all the thermal fatigue cracks originated from the surface of the samples, and further developed along both surface and cross-section. The flaking off of the compound layer directly caused the formation of the wide cracks but slightly influenced the longitudinal growth (Fig. 8a). In contrast, the thermal cracks formed in the compound-free layers showed narrow apices with longer dimension (Fig. 8b). For the SPGN sample, the higher $\varepsilon / \gamma$ ratio caused the higher surface brittleness $[11,12]$, meaning a stronger fracture tendency during thermal fatigue [12]. Since the higher hardness reduces the accumulation of plastic strains in the surface layer [23], the thermal crack advancement in the SPGN samples during heat cycling had a tendency to be suppressed by the higher hardness distribution in the longitudinal direction (Fig. 8c). Evidently, further surface deformation treatment on compound-free nitrided layer could reduce the thermal crack length without widen the crack origins (Fig. 8d). Taking account of the physical characteristic of each nitrided layer, it can be inferred that the excellent toughness and high hardness distribution in the surface layer are beneficial to resisting thermal fatigue, especially with regard to the crack propagation behavior.

\subsubsection{Softening behavior of the modified layer}

During thermal fatigue testing, the high frequency thermal and mechanical shock provided a unique softening condition for the surface-modified layers. To evaluate the stability of the modified layer, the surface hardness distribution was measured after thermal fatigue test of 100, 300 and 500 cycles (Fig. 9). At the initial stage of thermal fatigue testing, the peak hardness decreased and shifted from the surface to the subsurface. Decomposition of the compound layer and denitriding are the predominant factors in softening the single treated nitrided layers. Arising from the nitrogen diffusion in both directions driven by the steep nitrogen concentration gradient the shift of the microhardness peak occurred along with the thermal cycling treatment. The 
surface layer of the SPGN sample was more sensitive to denitriding and grain coarsening in comparison with that of TGN sample due to the higher nitrogen concentration gradient and ultrafine grain size. The hardness distribution in the CGNSP sample retained the original features but with lower magnitude. Increasing the thermal cycles up to 500, no obvious peak microhardness was found in the hardness distribution profile in each treated sample. The hardness in the case layer with a thickness of approximately $120 \mu \mathrm{m}$ was measured to be lower than that of the substrate, which meant a completely instability failure of the surface layers.

\section{Discussion}

\subsection{Thermal cracking}

Fig. 10 summarized the responses of the surface treatments to thermal checking under given thermal fatigue conditions. The mean width of the horizontal cracks as a function of thermal cycles clearly showed the surface thermal crack growing behavior (Fig. 10a). Overall observation shows that the mean width of the surface cracks was increased with increasing thermal cyclic numbers. The thermal cracks in the nitrided compound layers showed the faster widening rates, and the pre-shot peening promoted the cracks growth especially at the propagation stage (300-500 cycles). It is indicated that the compound layer consisting of the $\varepsilon-\mathrm{Fe}_{2-3} \mathrm{~N}$ and $\gamma^{\prime}-\mathrm{Fe}_{4} \mathrm{~N}$ phases exhibits a lower fracture toughness than the compound-free nitrided layer, and favors an easy crack nucleation due to the high internal stresses $[14,23]$. This supports the experimental evidence that, once nucleated, cracks propagated easily through the compound layer. Fig.10b shows the 3D profiles of the surface thermal cracks in each sample tested after 500 thermal cycles. The surface sunken profiles reflected the surface growth features and the depth of the thermal cracks. Coupled with the growth model of the cracks in the depth direction (Fig. 10c), the thermal checking behavior in each modified layer could be characterized. Formation of nitrided compound-free layers contributes to the suppressing of cracks widening on the surface, especially, further deformation on the compound-free layer by shot peening help moderate the cracks propagation. In this 
sense it is seemed that the combined treatment of controlled gas nitriding and surface severe deformation is an appropriate method to resist thermal checking. Nevertheless, thermal cycles generated the highest crack density in surface of the CGNSP sample, which would be the hidden problems of large areas failure due to the cracks merging after a sufficient number of thermal cyclic.

The formation of thermal cracks involves the cracks nucleation, initial growth, and proceeded crack growth, which produces surface destruction or surface delamination of the degraded material [6]. The present research focused on the thermal checking of the hot work die steels, and attempted to simulate the industrial application, especially for the non-reusable moulds. Many heat checks repair methods have been adopted on the mould or tool steel surface to maximize the lifetime before failure occurs [24-26]. However, once the cracks formed, the original stress state and microstructure would be destructed. Actually, there exists a gestation period before the thermal cracks nucleation, which is extremely important to the risk assessment of the working moulds. Surface condition restructure in the latter stage of the crack gestation (before crack nucleation) seems to be more efficient in prolonging the die lifespan and reducing the risk. Because the thermal cycling will bring about residual stresses in the surface layer and local stress concentration will cause the tensile stresses to exceed the tool steel yield stress, consequently, the nucleation of the cracks $[3,6,23]$. That means significant changes in surface residual stress states will take place as soon as the occurrence of the thermal crack nucleation. The surface residual stress states in our field-test results have proved the possibility of monitoring the crack nucleation by detecting the evolution of the surface residual stress of the moulds.

\subsection{Gas nitriding for die casting applications}

When designing a gas nitriding process for prolonging die life and improving performance in die casting applications, both the crack nucleation and propagation behavior, as well as other failure mechanisms (e.g. wear, erosion and corrosion) have to be considered. Recently, gas nitriding has been adopted to improve the wear performance [10,27], erosion [28,29], and corrosion resistance [30] of the hot work die 
steels. However, different perspectives with regard to the ability of gas nitriding in improving the thermal fatigue property have been reported $[3,6,14]$. Theoretically, the thermal fatigue resistance has a strong dependence on the surface nitrided microstructure, combination of hardness and toughness, as well as the state and distribution of the residual stress. The above results showed the thermal fatigue cracking behavior was under the influence of the inversion relationship between hardness and toughness in gas nitriding process. A desirable combination of hardness and toughness of the nitrided surface layer plays an important role in improving the thermal fatigue resistance. It is proved that an initial tensile residual stress state of a certain magnitude in the tool material surface may delay crack initiation, whereas an initial compressive residual stress of any level facilitates crack formation [23]. However, it is not applicable to explain the thermal fatigue behavior of the coated steels. It is demonstrated that increasing the compressive residual stress in the $\mathrm{WC}-\mathrm{Co} / \mathrm{CrN}$ coatings can significantly increase the number of cycles to thermal fatigue failure $[31,32]$. The crack initiation and propagation behavior of the coated steel is the result of the interaction of many factors such as the coating hardness, toughness, grain size and residual stress, etc. The higher compressive residual stress will resist or delay the relaxation of the tensile stress during the cold phase of die casting cycle. Since both nitriding and shot peening can generate residual compressive stress in steel surface, a combined residual compressive stress is expected after CGNSP treatment, which can protect the surface of the mould from cracking.

\section{Conclusions}

Thermal fatigue evaluation of AISI H13 steels surface modified by gas nitriding with pre- and post-shot peening was carried out focusing on the thermal cracking behavior. The conclusions that can be drawn from this investigation are,

(1) The formation of the compound layer promotes the propagation of the thermal cracks along the surface due to its brittleness, while the relatively higher hardness distribution could slow down the crack propagation in depth direction. Instead, the compound-free nitrided layer showed more excellent thermal fatigue property 
regarding suppressing the surface propagation of the thermal cracks but inadequate capability in inhibiting crack growing to the inner substrate.

(2) The resistance against thermal crack propagation along the depth direction of the modified steels was further improved after gas nitriding with pretreatment of shot peening. The surface thermal cracking, however, was accelerated due to the large amount of defects formed in both shot peening and nitriding which resulted in stress concentration during thermal cycling.

(3) Of the processes evaluated, combined treatment of controlled gas nitriding and post-shot peening enabled the improvement of thermal fatigue cracking resistance in both surface and inner, but generated the higher surface crack density. The good combination of hardness and toughness, as well as the expected enhanced compressive residual stress caused the least destructive during thermal fatigue.

\section{Acknowledgements}

The authors gratefully acknowledge the support from the National Natural Science Foundation of China (Grant No. 51701122), the Hitachi-SJTU joint research program and Baotou-SJTU Innovation Guidance (No. 18H100000174).

\section{References}

[1] L.J.D. Sully, ASM International. vol. 15. Metals Park. OH (1988) 286-295.

[2] J.R. Davis, ASM Specialty Handbook: Tool Materials, ASM international, 1995.

[3] A. Persson, S. Hogmark, J. Bergström, Thermal fatigue cracking of surface engineered hot work tool steels, Surf. Coat. Technol. 191 (2005) 216-227.

[4] B. Miquel, S. Jean, S. Le Roux, P. Lamesle, F. Rézaï-Aria, Heat-checking of hot work tool steels, Eur. Struct. Integr. Soc. 29 (2002) 185-193.

[5] D. Klobčar, J. Tušek, B. Taljat, Thermal fatigue of materials for die-casting tooling, Mater. Sci. Eng. A 472 (2008) 198-207.

[6] D. Klobčar, L. Kosec, B. Kosec, J. Tušek, Thermal Fatigue of Materials for Die Casting Tooling, Eng. Fail. Anal. 20 (2012) 43-53.

[7] Y.A. Min, X.C. Wu, L.P. Xu, W.J. Tang, S.K. Zhang, G. Wallner, D. Liang, Y.Y. 
Feng, Influence of different surface treatments of H13 hot work die steel on its thermal fatigue behaviors, J. Shanghai Univ. 5 (2001) 326-330.

[8] B.D. Beake, L. Ning, C. Gey, S.C. Veldhuis, A. Komarov, A. Weaver, M. Khanna, G.S. Fox-Rabinovich, Wear performance of different PVD coatings during hard wet end milling of H13 tool steel, Surf. Coat. Technol. 279 (2015) 118-125.

[9] H. Yang, X. Wu, G. Cao, Z. Yang, Enhanced boronizing kinetics and high temperature wear resistance of H13 steel with boriding treatment assisted by air blast shot peening, Surf. Coat. Technol. 307 (2016) 506-516.

[10] B. Wang, X. Zhao, W. Li, M. Qin, J. Gu, Effect of nitrided-layer microstructure control on wear behavior of AISI H13 hot work die steel, Appl. Surf. Sci. 431 (2018) 39-43.

[11] T. Bell, Source book on nitriding, ASM, Met. Park. OH (1977) 266.

[12] E.J. Mittemeijer, M.A.J. Somers, Thermochemical Surface Engineering of Steels: Improving Materials Performance, Elsevier, 2014.

[13] D. Kundalkar, M. Mavalankar, A. Tewari, Effect of gas nitriding on the thermal fatigue behavior of martensitic chromium hot-work tool steel, Mater. Sci. Eng. А 651 (2016) 391-398.

[14] M. Pellizzari, A. Molinari, G. Straffelini, Mater. Sci. Eng. A 352 (2003) 186194.

[15] S.S. Akhtar, A.F.M. Arif, B.S. Yilbas, A.K. Sheikh, Thermal fatigue resistance of gas and plasma nitrided 41CrAlMo7 steel, J. Mater. Eng. Perform. 19 (2010) 347-355.

[16] B. Wang, B. Liu, X. Zhang, J. Gu, Enhancing heavy load wear resistance of AISI 4140 steel through the formation of a severely deformed compound-free nitrided surface layer, Surf. Coat. Technol. 365 (2018) 89-95.

[17] W.P. Tong, N.R. Tao, Z.B. Wang, J. Lu, K. Lu, Nitriding iron at lower temperatures, Science (80). 299 (2003) 686-688.

[18] B. Wang, S. Sun, M. Guo, G. Jin, Z. Zhou, W. Fu, Study on pressurized gas nitriding characteristics for steel 38CrMoAlA, Surf. Coat. Technol. 279 (2015) 60-64. 
[19] W.P. Tong, N.R. Tao, Z.B. Wang, H.W. Zhang, J. Lu, K. Lu, The formation of $\varepsilon^{-}$ Fe3-2N phase in a nanocrystalline Fe, Scr. Mater. 50 (2004) 647-650.

[20] W.P. Tong, Z. Han, L.M. Wang, J. Lu, K. Lu, Low-temperature nitriding of $38 \mathrm{CrMoAl}$ steel with a nanostructured surface layer induced by surface mechanical attrition treatment, Surf. Coat. Technol. 202 (2008) 4957-4963.

[21] J. Sun, W.P. Tong, H. Zhang, L. Zuo, Z.B. Wang, Evaluation of surface-modified 20CrMo by plasma nitriding coupled with ion sputtering and SMAT, Surf. Coat. Technol. 213 (2012) 247-252.

[22] F. Ashrafizadeh, Influence of plasma and gas nitriding on fatigue resistance of plain carbon (Ck45) steel, Surf. Coat. Technol. 174 (2003) 1196-1200.

[23] A. Persson, S. Hogmark, J. Bergström, Simulation and evaluation of thermal fatigue cracking of hot work tool steels, Int. J. Fatigue 26 (2004) 1095-1107.

[24] X. Tong, M. Dai, Z. Zhang, Thermal fatigue resistance of H13 steel treated by selective laser surface melting and CrNi alloying, Appl. Surf. Sci. 271 (2013) 373-380.

[25] D. Cong, H. Zhou, Z. Ren, Z. Zhang, H. Zhang, C. Meng, C. Wang, The thermal fatigue resistance of $\mathrm{H} 13$ steel repaired by a biomimetic laser remelting process, Mater. Des. 55 (2014) 597-604.

[26] J.W. Murray, A.T. Clare, Repair of EDM induced surface cracks by pulsed electron beam irradiation, J. Mater. Process. Technol. 212 (2012) 2642-2651.

[27] G. Castro, A. Fernández-Vicente, J. Cid, Influence of the nitriding time in the wear behaviour of an AISI H13 steel during a crankshaft forging process, Wear 263 (2007) 1375-1385.

[28] S.-H. Chang, T.-P. Tang, K.-T. Huang, J.-K. Chen, Effects of post-oxidizing treatment on melting loss and corrosion resistance of gas nitrided AISI H13 tool steel, ISIJ Int. 52 (2012) 499-504.

[29] S.-H. Chang, T.-P. Tang, Y.-C. Chen, J.-K. Chen, Enhancement of erosion resistance on AISI H13 tool steel by oxynitriding treatment, ISIJ Int. 49 (2009) $421-424$.

[30] S.-H. Yeh, L.-H. Chiu, H. Chang, Effects of gas nitriding on the mechanical and 
corrosion properties of SACM 645 Steel, Engineering 03 (2011) 942-948.

[31] R.T.R. McGrann, D.J. Greving, J.R. Shadley, E.F. Rybicki, T.L. Kruecke, B.E. Bodger, The effect of coating residual stress on the fatigue life of thermal spraycoated steel and aluminum, Surf. Coat. Technol. 108-109 (1998) 59-64.

[32] C. Kirchlechner, K.J. Martinschitz, R. Daniel, C. Mitterer, J. Donges, A. Rothkirch, M. Klaus, C. Genzel, J. Keckes, X-ray diffraction analysis of threedimensional residual stress fields reveals origins of thermal fatigue in uncoated and coated steel, Scr. Mater. 62 (2010) 774-777. 


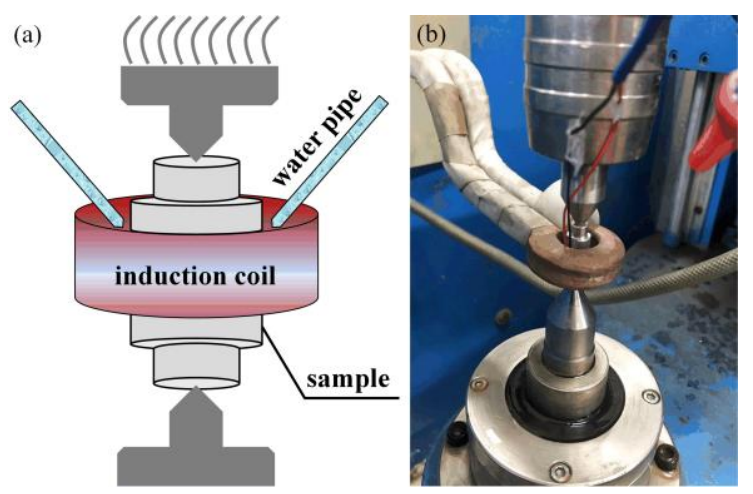

Fig. 1

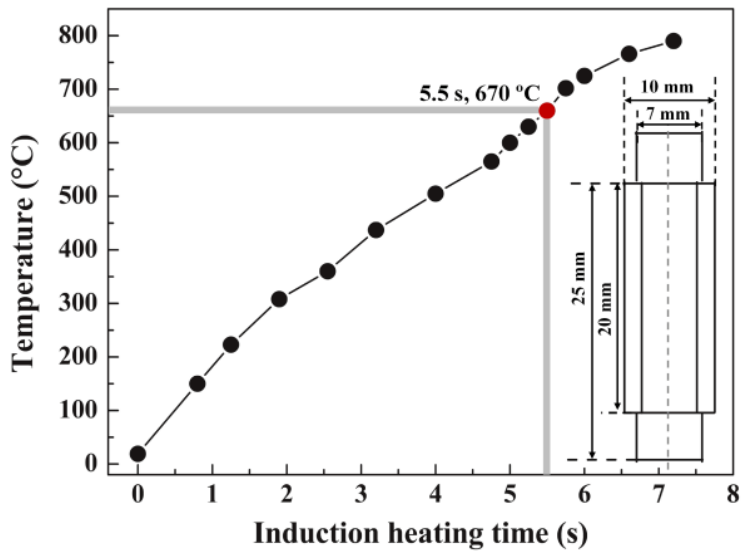

Fig. 2

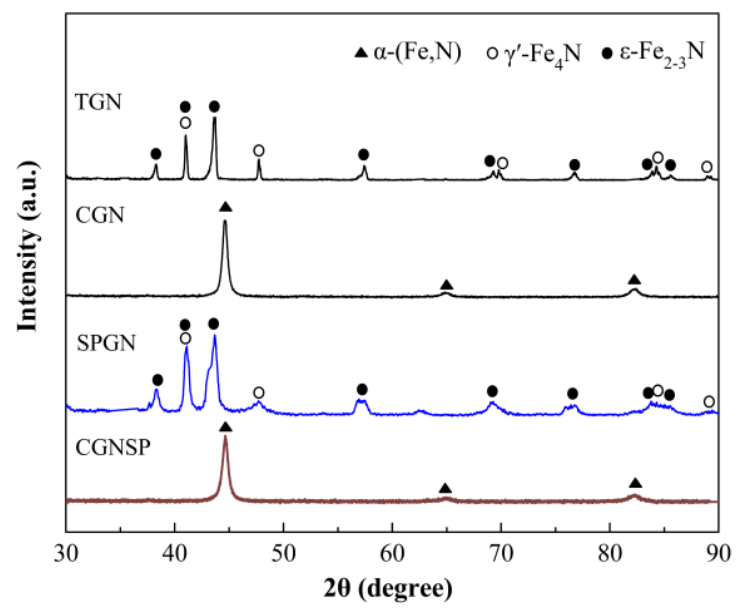

Fig. 3 


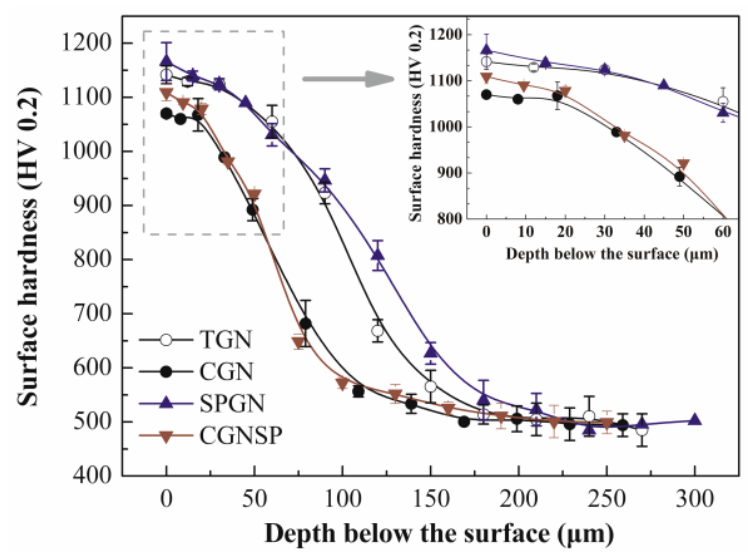

Fig. 4

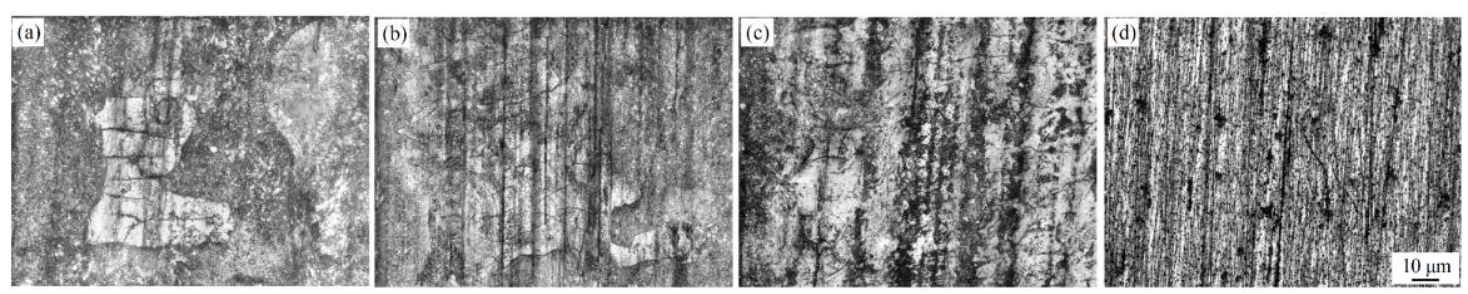

Fig. 5

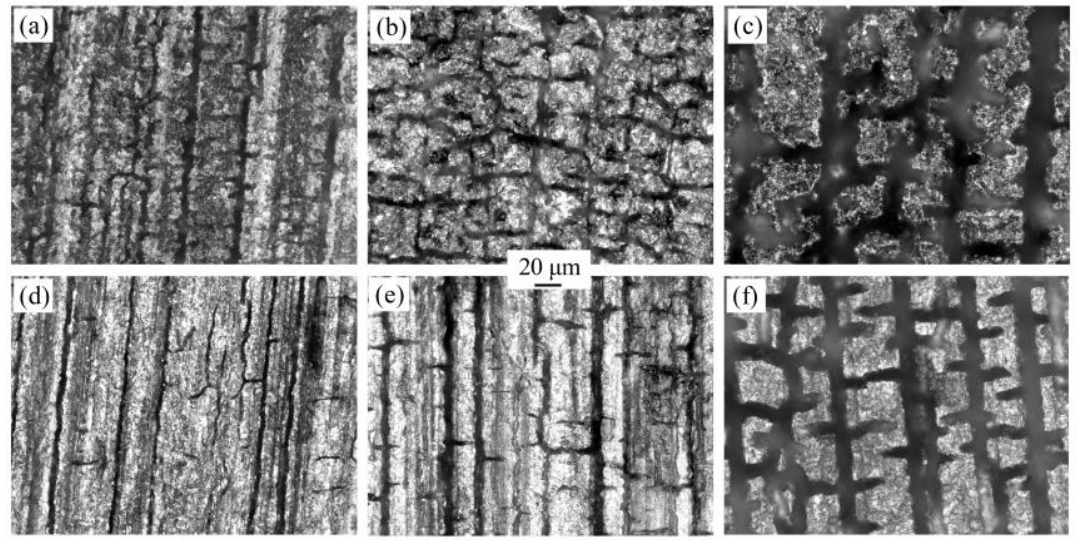

Fig. 6 

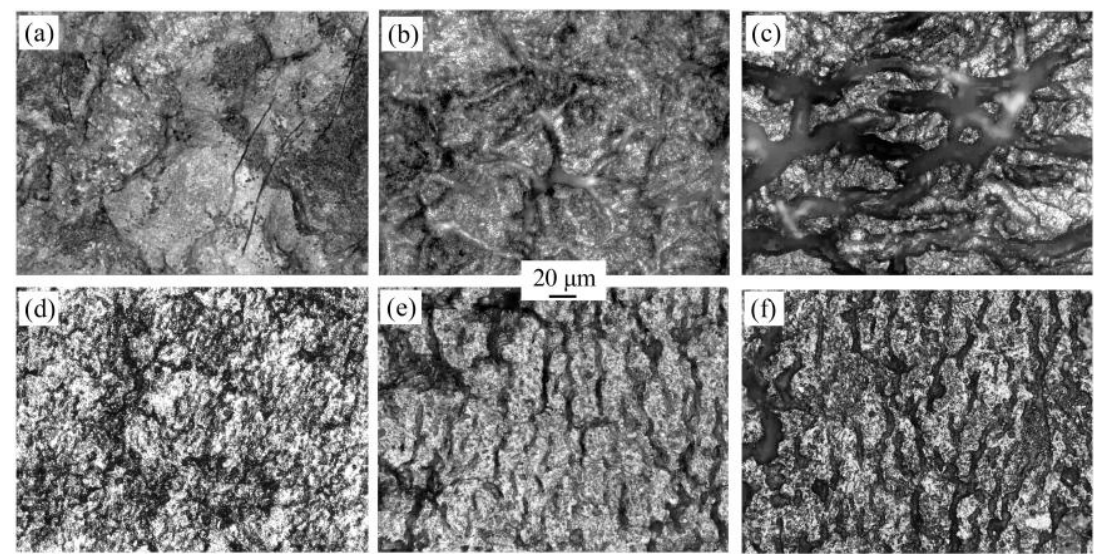

Fig. 7
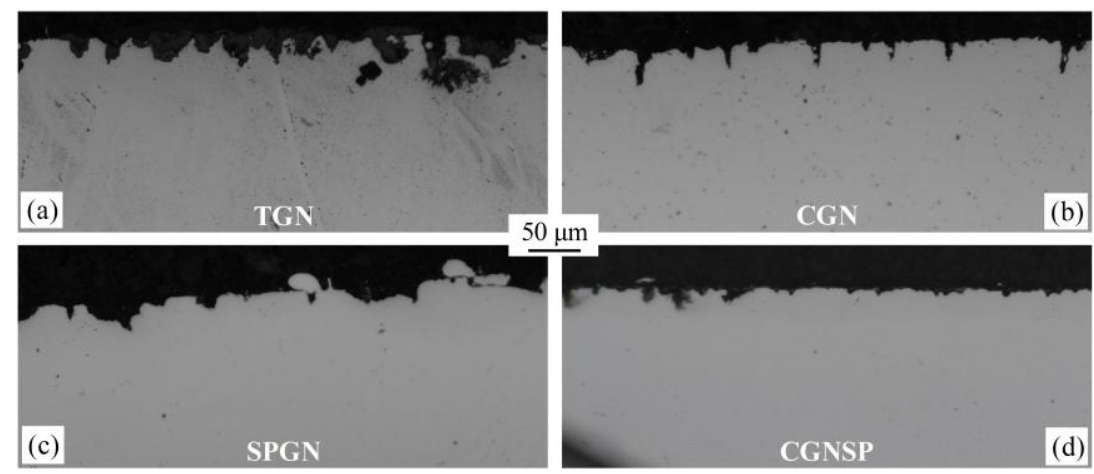

Fig. 8
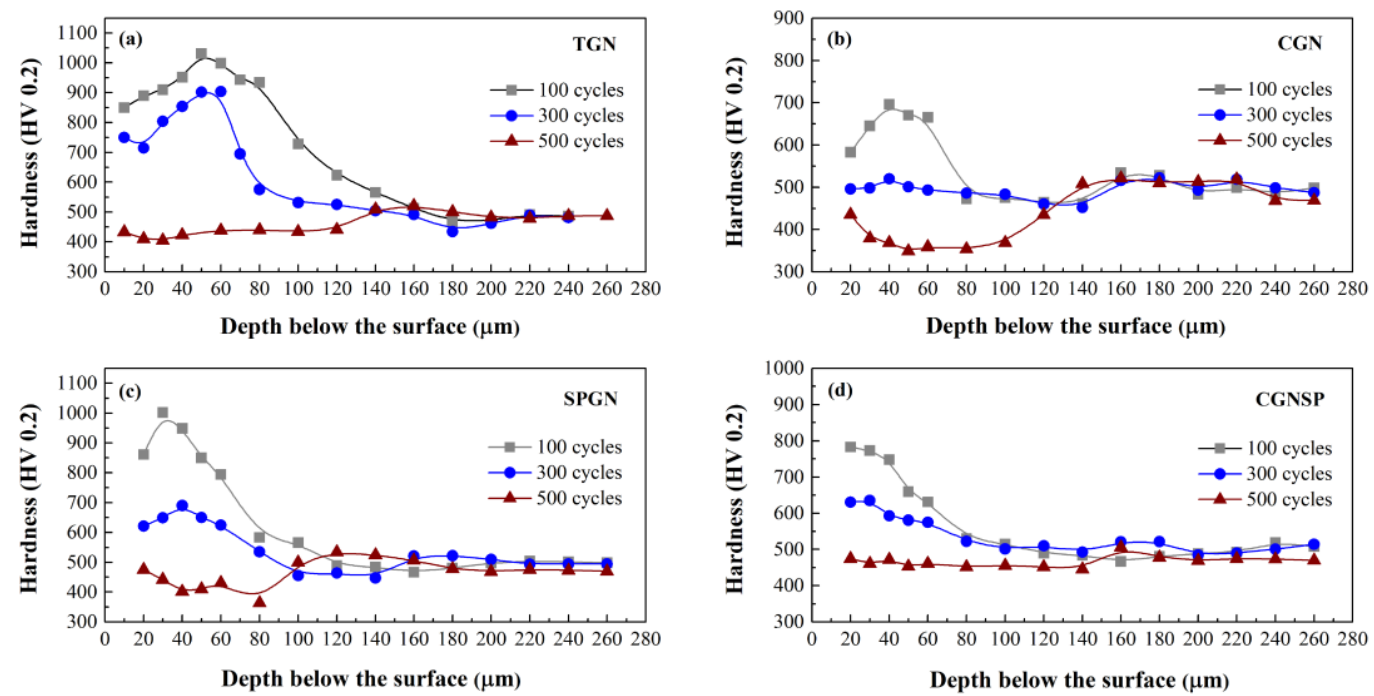

Fig. 9 

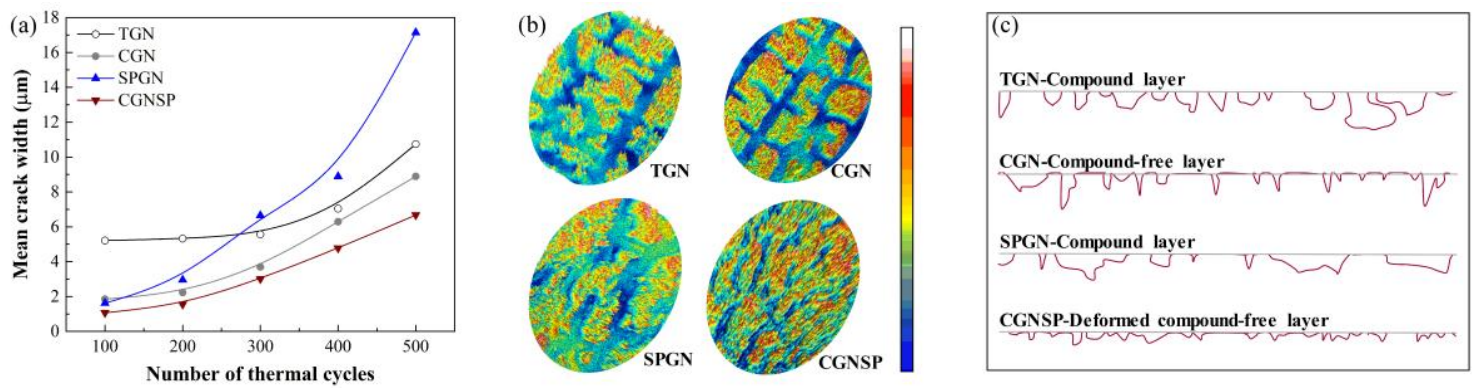

Fig. 10 